\title{
Analysis on the Influencing Factors of the Development of Chinese Fresh Cold Chain Logistics under E-Commerce Background
}

\author{
Huifang Bai ${ }^{1} \&$ Qian Guo ${ }^{1}$ \\ ${ }^{1}$ College of Management, Northwest Minzu University, Lanzhou, China \\ Correspondence: Huifang Bai, Lecturer, College of Management, Northwest Minzu University, Lanzhou, Gansu, \\ China.
}

Received: January 27, 2017

Accepted: February 5, $2017 \quad$ Online Published: February 13, 2017

doi:10.5430/jms.v8n1p55

URL: http://dx.doi.org/10.5430/jms.v8n1p55

This research was supported by "The Fundamental Research Funds for the Central Universities of Northwest Minzu University (Grant No. 319201300910)" and "The Science and Technology Development Program of Lanzhou (Grant No. 2015-2-96)".

\begin{abstract}
With the rapid development of Internet technology, e-commerce began to penetrate in various fields, the fresh electricity providers rose rapidly. At the same time with the awakening of consumer awareness, people's demand for fresh produce increased drastically, and people pay more attention to food safety and freshness, but the development of fresh cold chain logistics can not meet the demand of fresh e-commerce market. In this paper, the factors affecting the development of fresh cold chain logistics are sorted out, and the influencing factors are analyzed systematically through ISM model. Finally, we put forward the way to promote the development of cold chain logistics.
\end{abstract}

Keywords: E-commerce, freshness, cold chain logistics, influencing factors

\section{Introduction}

At present, with the development of Internet technology, e-commerce has gradually become a new business model with the traditional business model. Under this background, this greatly enhanced the convenience of people shopping, at the same time, e-commerce has gradually penetrated into all walks of life, China's fresh market is seen as the last piece blue ocean of electricity industry, fresh electricity business is also known as the next 100 billion market. According to the China Electronic Commerce Research Center monitoring data, it shows that in 2013 the national fresh electricity trading volume reached 13 billion in 2014 reached 26 billion Yuan. Compared with 2013, the growth rate reached $100 \%$. In 2015, it reached a new high record, 56 billion. It is expected to reach 128.3 billion in 2018. Driven by the forceful market, China's major electric business also took frequent action, increased investment. Currently, there are three camps in the market of fresh electricity supplier in China: the first is the big fresh electricity channel represented by TMALL, JingDong. The second is based on the vertical fresh electricity business platform, like Originally life network, COFCO I buy nets. The third category is the traditional supermarket 020 fresh electricity providers. However, the development of fresh electricity supplier status is not ideal. As of 2016, there are more than 4,000 fresh electricity providers in China, only $1 \%$ of them earn the profits, $4 \%$ keep flat, $88 \%$ loss the electricity business, and the remaining $8 \%$ a huge loss.

The rapid development of fresh electricity providers is mainly restricted by the current development of cold chain logistics, only the rapid development of fresh cold chain logistics, to enable consumers to truly rest assured that the purchase of fresh electricity business platform for goods, thereby promoting fresh electricity providers Of the rapid development. However, Chinese fresh cold chain logistics is affected by various complicated factors which affect each other. Given this, based on the analysis of the development of China's cold chain logistics, we sort out and analyze the impact of the various factors systematically. Then find the right path to promote cold chain logistics and fresh electricity providers, which is of great significance to form a win-win development.

\section{Analysis of the Restricting Factors of the Development of Fresh Cold Chain Logistics}

Cold chain logistics refers to the logistics process of the frozen food in the production and processing, storage and transportation, sales until the hands of consumers, which is always in the low-temperature environment to ensure 
food freshness, reduce the loss. Fresh products have many types, including vegetables, fruits, meat, aquatic products and dry goods. With the economic progress and the consumer attitudes changes, as well as the convenience brought by the emergence of e-commerce, consumer demand for fresh market is growing. However, in the strong demand, the development of fresh cold chain logistics is far behind the development of e-commerce. The reasons, mainly in the following aspects of the influencing factors.

\subsection{Third-party Logistics Enterprise Scale Factor}

Under the background of e-commerce, the process of the fresh food supply chain greatly shortened, it can connect agricultural producers and consumers through the e-commerce platform (Figure 1). The integration of the entire supply chain depends on the electronic business platform online mainly, the cold chain logistics to complete the entire transaction offline. It can be seen from the chart. The cold chain logistics business is bound to provide fresh products, warehousing, transportation, packaging, distribution and a series of integrated services under the E-commerce background.

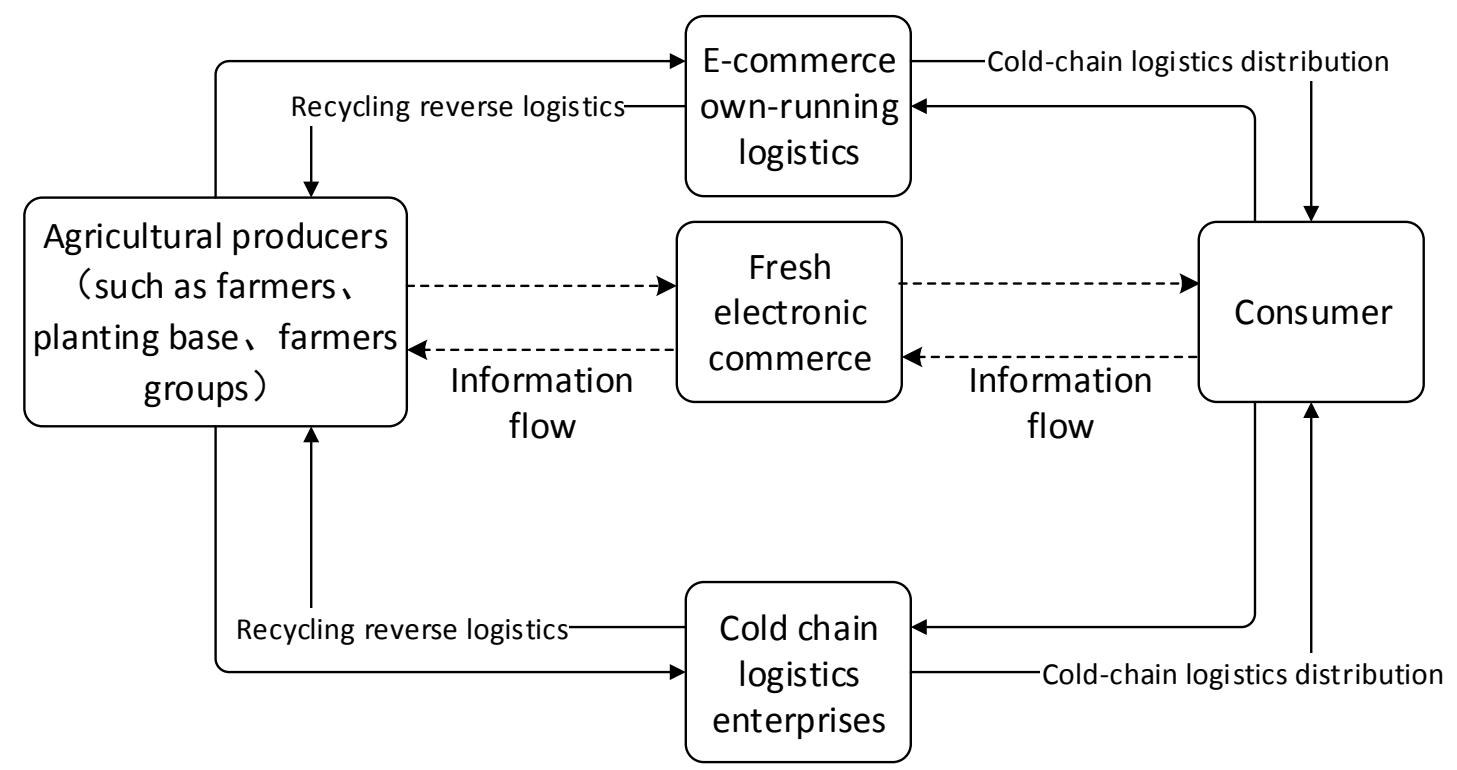

Figure 1. The supply chain structure of Fresh electricity commerce

However, the specialized third-party cold-chain logistics enterprises in China were generally small, scattered, chaotic, inferior. These enterprises did not form a complete service chain and could not provide integrated cold chain logistics services, which significantly restricted rapid development of fresh e-commerce. Therefore, some of the electricity business will take self-support model for cold chain logistics operations. Self-logistics has advantages in the provision of integrated logistics services and the control of all aspects of logistics, but in the background that the current demand for fresh electricity products is small, customers are extremely scattered and other characteristics, the cold chain logistics is difficult to form scale effect.At the same time, resulting in a large-scale investment of self-logistics, a large number of idle resources and other phenomena, leading to electric operators to operate difficultly.

\subsection{Standardization Factor}

E-commerce environment for cold chain logistics operations mainly concentrated in the express industry, November 9, 2015, the Chinese Ministry of Commerce announced the first occupation standard in the field of e-commerce logistics industry named E-Commerce Logistics Service Standards, and September 1, 2016, it officially implemented. The development of the standard not only regulate the logistics operation of e-commerce enterprises to enhance the quality of electrical and physical distribution services but also promote the development of electronic business logistics to ensure the healthy and sustainable development of electricity providers.

However, the standard clearly does not apply to cold chain logistics. The lack of standardization of cold chain logistics under e-commerce environment, resulting in the randomness of fresh products in the packaging, transportation, storage, distribution and other pivotal aspects. Many truck drivers interrupt the power supply in transit 
to reduce power consumption to reduce costs, or directly use the "flat car plus ice" approach to carry out cold chain transport. In the packing, sometimes only use a foam box to keep a certain degree of insulation. This cold chain logistics transportation can not guarantee food quality, at the same time because it can not meet consumer expectations and thus lead to the risk of customer loss, which will undoubtedly bring fresh electricity business a serious blow.

\subsection{Supervision Mechanism Factor}

The standards related cold chain are more than 200 in China, but the lack of supervision, poor corporate governance, the food safety supervision in cold chain logistics is almost blank. Once the company violated the rules of the cold chain transport, storage and equipment, and other detailed provisions, companies do not face strict fines and legal sanctions. Leading to the chaotic development of China's cold chain logistics, food storage, transportation and distribution of fresh food companies are often questioned by consumers without the authority of government regulators, which in turn affect their rapid development.

\subsection{Infrastructure and Technology Factor}

Cold chain logistics infrastructure is badly inadequate, refrigerated trucks, refrigerated containers and other infrastructure can not meet the rapid development of e-commerce far. According to the July 13, 2016 China's cold chain logistics network reported that China's refrigerated trucks is estimated to be 9.3 million, equivalent to only the growth of America or Europe, the per capita possession of refrigerated trucks is only one-tenth of Japan. Cold storage is also very weak, although the total number of cold storage is flat with the United States, cold storage is about 93 million cubic meters, but the per capita cold storage is only accounted for one-fifth of the United States, a quarter of Japan, one- third of German. And most of the cold storage construction are antique, some even exceeded again use fixed of the year. They can not meet the modernization requirements of fresh electricity providers of the cold chain.

There are many types of fresh products, including vegetables, fruits, meat, aquatic products and dry goods. Each category also contains a large number of different varieties, each species of fresh need different temperature, humidity and choice of storage packaging methods, preservation time. Therefore, it is necessary to put forward the strict requirements of the preservation facilities and equipment and cold chain logistics management coordination, and transport time control.

\subsection{Informatization Factor}

This information mainly refers to the information network system between the cold chain logistics enterprises and e-commerce platform for enterprises. It is mainly in the form of electronic data interchange to complete a variety of business activities and related service activities. It is the essential content to achieve fresh e-commerce information flow. Excellent logistics informatization is the biggest difference between the electricity supplier of fresh cold chain logistics and fresh raw materials. In the background of e-commerce, it is particularly critical to build logistics information system, because the fresh electricity business user needs are real-time, fragmentation and high-frequency. Only establish the information system between the electricity providers and cold chain logistics enterprises, can it be on time to send the fresh food to the hands of consumers. The establishment of information systems on the big data, networking technology, can better integrate logistics needs, protect the level of logistics services while improving logistics efficiency and reduce logistics costs.

\subsection{Talent Factor}

Cold chain logistics personnel requirements are relatively high, these technical staff and management staff who are engaged in cold chain logistics have to not only understand the relevant theoretical knowledge but also need to have professional experience. However, the vast majority of practitioners in China did not receive the relevant cold chain logistics skills training before employment, many of them are directly from the ordinary logistics enterprises to switch to cold chain logistics transport, storage, packaging, distribution and other sectors. They lack the appropriate expertise and skills, resulting in the general low level of service of cold chain logistics industry.

\section{Based on the ISM Model of Fresh Cold Chain Logistics Impact Factors System Analysis}

The influencing factors of the development of the cold chain logistics affect each other, and are systematic. Therefore, in order to promote the rapid and healthy development of fresh cold chain logistics, it is necessary to make a systematic analysis of the influencing factors, and then provide the basis for the countermeasures. There are five steps in this part. 


\subsection{Factor Relations Grid Graph}

By analyzing the influence relations between the each two factors, the factor binary relations grid graph is drawn, as shown in Figure 2.

\begin{tabular}{|c|c|c|c|c|c|}
\hline A & A & A & (A) & A & 1. Third-party logistics enterprise scale \\
\hline & $\mathrm{V}$ & $\mathrm{V}$ & $X$ & \multicolumn{2}{|c|}{ 2.Standardization factor } \\
\hline & $(\mathrm{V})$ & $(\mathrm{V})$ & \multicolumn{3}{|c|}{ 3. Supervision mechanism factor } \\
\hline A & $\mathrm{V}$ & \multicolumn{4}{|c|}{ 4. Infrastructure \& technology factor } \\
\hline A & 5. In & rmat & ation & actor & \\
\hline
\end{tabular}

6. Talent factor

Figure 2. Factor binary relations grid graph

\subsection{Reachability Matrix}

According to the factor binary relations grid graph, the reachability matrix is written.

$$
\begin{aligned}
& \mathrm{M}= \\
& 1 \\
& 2 \\
& 3 \\
& 4 \\
& 5 \\
& 6
\end{aligned}\left[\begin{array}{llllll}
1 & 2 & 3 & 4 & 5 & 6 \\
1 & 0 & 0 & 0 & 0 & 0 \\
1 & 1 & 1 & 1 & 1 & 0 \\
1 & 1 & 1 & 1 & 1 & 0 \\
1 & 0 & 0 & 1 & 1 & 0 \\
1 & 0 & 0 & 0 & 1 & 0 \\
1 & 0 & 0 & 1 & 1 & 1
\end{array}\right]
$$

Because the factors 2 and 3 has strong connection relations, removing the factor 3's rows and columns, the reduced matrix is obtained:

$$
\mathrm{M}^{\prime}=\begin{aligned}
& 1 \\
& 2 \\
& 4 \\
& 5 \\
& 6
\end{aligned}\left[\begin{array}{lllll}
1 & 2 & 4 & 5 & 6 \\
1 & 1 & 1 & 1 & 0 \\
1 & 0 & 1 & 1 & 0 \\
1 & 0 & 0 & 1 & 0 \\
1 & 0 & 1 & 1 & 1
\end{array}\right]
$$

\subsection{Hierarchical Processing of the Reduced Matrix}

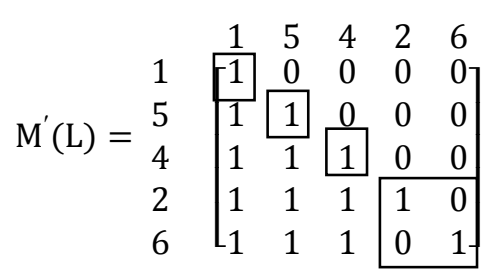

In this matrix, the factors are divided into four levels: factor 1 belongs to the first level; factor 5 belongs to the second level; factor 4 belongs to the third level; factor 2, 3, and 6 belong to the fourth level.

\subsection{Multilevel Hierarchical Directed Graph}

According to the factors' layering, multilevel hierarchic directed graph is drawn, as shown in Figure 3. 


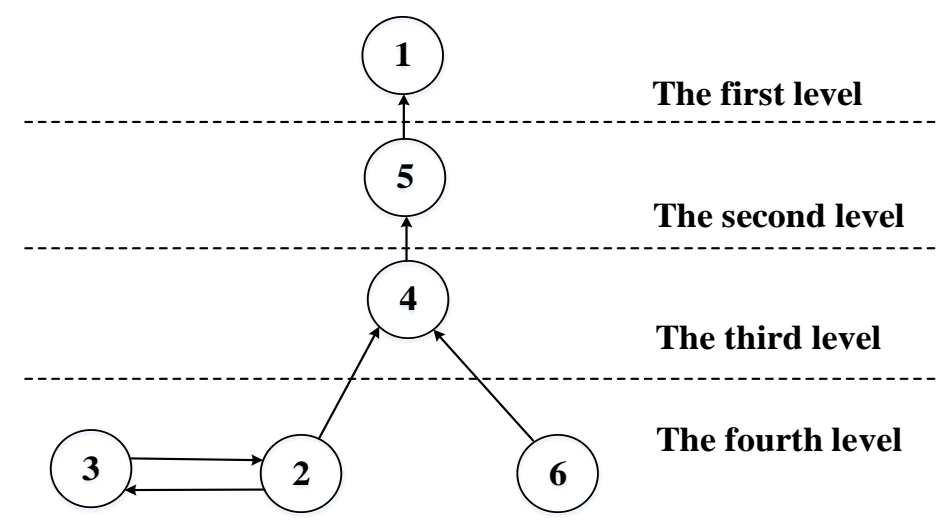

Figure 3. Multilevel hierarchical directed graph

\subsection{The Interpretation Structure Model of Cold-Chain Logistics Influence Factors}

Based on the multilevel hierarchical directed graph, we can get the Interpretation Structure Model(ISM) of influencing factors, as shown in Figure 4.

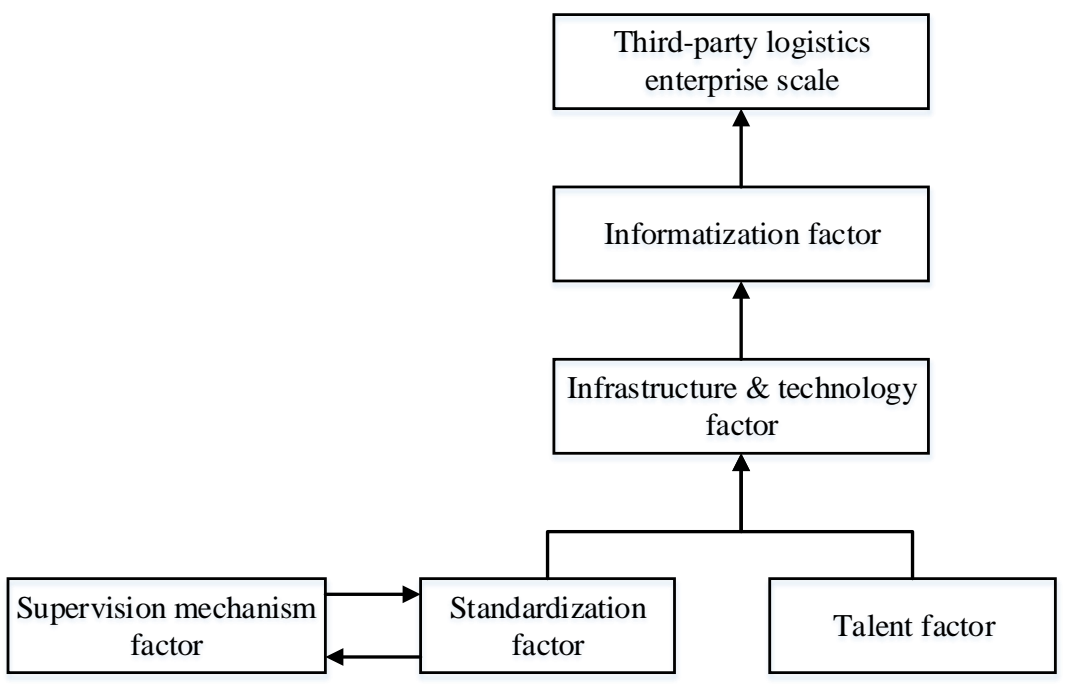

Figure 4. The ISM model of cold-chain logistics influence factors

\section{The Way to Promote the Development of Electronic Cold Chain Logistics}

\subsection{Construct a Decent Environment for the Development of Cold Chain Logistics}

Through the analysis of ISM model of influencing factors, it is found that the establishment of talent factor, standardization factor, and supervision mechanism factor is the macro environment of cold chain logistics development, and good macro environment can guarantee the healthy and rapid development of cold chain logistics. It is the first step to take actions on the establishment of the macro-environment mainly from the following two aspects:

First, government departments should establish a sound cold chain logistics laws, regulations and related standardization system as soon as possible, and through the establishment of regulatory mechanisms to protect the implementation and standardization of the codices and regulations and standardization. At the same time, the government should give appropriate policy support to stimulate the healthy development of cold chain logistics enterprises.

Second, increase professional training in the cold chain logistics. Personnel training is mainly from the academic 
education, vocational training and qualification these three aspects, no matter from which aspect, we must pay attention to the rationalization of knowledge structure in personnel training. It is necessary to train skills and management knowledge related cold chain logistics, cultivate e-commerce, information and other aspects of lore. So the talent in cold chain logistics industry could adapt to the future rapid development of fresh electricity supply chain system.

\subsection{Infrastructure and Information Is the Basis for Sustainable Development of Cold Chain Logistics}

Infrastructure and information factors in the middle layer of the ISM model, these two factors are the fundamental factors to construct the modern cold chain logistics and ensure the sustainable development of cold chain logistics.

First of all, the government should increase investment in technology, overall plan the distribution of the cold storage center and the establishment of the transport equipment and goods monitoring and quality control infrastructure. Secondly, the cold chain logistics enterprises should actively update the transportation equipment, introduce advanced and efficient technology, advanced cold storage infrastructure to preserve fresh products. Finally, the establishment of the modern significance of information technology. Electronic cold chain logistics information does not only connect e-commerce platform but also with the upstream agricultural. Increase the cold chain logistics information exchange of each node, so that producer understand the current and future market trends, managers can grasp the various fresh produce output, shelf life, and other characteristics, it is conducive to the commencement of commercial activities.

\subsection{Strengthening and Expanding Third-party Logistics Enterprises Are the Direct Performance of the Rapid Development of Cold Chain Logistics}

The use of self-logistics to develop cold chain logistics business is bounded to bring a financial burden to fresh electricity supplier, it will result in the waste of resources in the off-season sales, so the choice of third-party logistics will become a trend. At present, the cold chain logistics investment is big. It is difficult to convert from a single logistics enterprises into large-scale integrated logistics establishments, third-party cold-chain logistics companies can achieve the purpose of strengthening and expanding through resource integration. Third-party logistics establishments analyze market demand, market positioning of their services, focus on the development of its core services, then work with other cold-chain logistics companies to integrate resources to form complementary advantages, the establishment of strategic alliances, and thus achieve win-win business interests.

\section{Concluding Remarks}

This paper analyzes the factors that influence the development of cold chain logistics in the background of China's electricity business. We then systematically sorts the influencing factors through ISM model and draws three ways to promote the development of cold chain logistics in China according to the Four-story diagram, which is of important significance to the rapid development of China's fresh electricity providers. However, this article still has its shortcomings, such as the choice of factors may not be comprehensive, ISM analysis of the binary relationship between factors may be ill-considered, these are the places where we still need to improve.

\section{References}

China's cold-chain logistics network. (2016). When the cross-border fresh trade is hot, what challenges will the cold storage face in China? Retrieved July 13, 2016, from http://www.cclen.com/shtmlnewsfiles/ecomnews/458/2016/201671300543745102.shtml

Lai, D. (2016). The problems and the countermeasures of cold-chain logistics development. Journal of Hubei University of Economics (Humanities and Social Sciences), 13(11), 61-62.

Ma, J., \& Yi, X. (2016). Did small fresh electronic-commerce enterprises invest money in wrong projects? Southern Metropolis Daily. $\quad$ Retrieved October 18, 2016, from http://epaper.oeeee.com/epaper/D/html/2016-10/18/content_85487.htm\#article

Tong, H. (2016). Analysis on fresh fruits and vegetables supply chain mode based on internet + . Logistics Engineering and Management, 38(12), 97-99.

Wu, Q. (2011). The current situation and the countermeasures of China's cold chain logistics development. China Business and Market, (2), 24-28.

Zhang, J., \& Huang, Q. (2015). Analysis of cold chain logistics in fresh e-commerce market. Logistics Technology, 34(3), 30-31, 46. 